\title{
A Serious Game with Geolocalition to Support Learning of Children with Autism and Learning Difficulties
}

\author{
Salatiel D. Silva ${ }^{1}$, Ademar. F. Sousa Neto ${ }^{2}$, Francisco M. Mendes Neto ${ }^{1}$, \\ Rodrigo M. de Lima ${ }^{3}$, Karla R. A. Demoly ${ }^{1}$ \\ ${ }^{1}$ Software Engineering Laboratory - Federal Rural University of Semi - Arid \\ ${ }^{2}$ Intelligent Software Engineering Group - Federal University of Campina Grande \\ ${ }^{3}$ Don Bosco Higher Education Unit \\ \{salatiel.dantas, miltonmendes, karla.demoly\}@ufersa.edu.br, \\ ademar.sousa@virtus.ufcg.edu.br, \\ rodrigo.lima@undb.edu.br
}

\begin{abstract}
People with Autism Spectrum Disorder (ASD) have characteristics described as the disability to relate to others, communication disorders, and obsessive concern about what is unchanging. Therefore, this paper aims to present an application for mobile devices, in a serious game format, whose purpose is to aid the autistic children teaching-learning process, also seeking to reduce their isolation tendencies. Also, it shows both ontologies, and the Multiagent System integrated into the application. The validation occurred with autism specialists through questionnaires. The results indicate that the proposed application presents the potential to reach its objectives.
\end{abstract}

Keywords: Autism. Augmented Reality. Virtual Reality. Serious Games. Ontologies.

\section{Introduction}

Autistic Spectrum Disorder (ASD) is a behavioral syndrome with different etiologies that profoundly affects the child development process [Association et al. 2014]. Children ASD present stereotyped behavior and characteristics such as emotional apathy and communication restrictions, making it challenging to establish interpersonal relationships [Clinical Protocol 2018]. Such behavior result in isolation, leading to lost opportunities for social development [Camargo and Bosa 2009].

To fill educational and social gaps of people with ASD, Valente (1997) proposed using information technologies, claiming to be an alternative that can better meet needs. To expand communication, language, and autonomy, people with ASD, Passerino (2005) suggests it uses computational environments. Thus, it allows sharing between subjects to enable the construction of knowledge by improving cognitive and socio-affective dimensions.

Starting there, experts use digital games to improve people's development, knowledge, cognitive, and collaborative skills [Brom et al. 2011]. To autistic people, the game's can transmit security, encouraging communication and learning [Souza 2016]. Recently, the applications are more attractive and immersive using computational techniques. Among these technologies, we can mention Augmented Reality (AR), feedback system, rewards, Virtual Reality (VR), among others. The interactive learning environments development disseminates these technologies. According to Braga (2001), these 
techniques provide rich and interactive environments that excite curiosity, increasing enthusiasm for its use.

Therefore, the current paper brings the following central research question: Can a Serious Geolocalized Game be used to minimize the time of social isolation and assist in the learning of children with Autism Spectrum Disorder? This paper presents an application based in serious games that use geoprocessing, AR, and VR technologies to assist in learning, and, besides, minimize isolation time of children with ASD, to solve this problem.

The remainder of this paper is structured as follows. Section 2 provides the concepts background involved in the application design. Section 3 reports on related work described by respective techniques and objectives. Section 4 describes application components in detail. Section 5 presents a ontologies set and a multi-agent system responsible for adapting games media to player's profiles. Section 6 presents games validation. Conclusions and discussion of research later stages in Section 7.

\section{Background}

\subsection{Autism}

Research carried out by the Center for Disease Control and Prevention (CD), the United States, showed that in 2014, one in fifty-nine children has TEA [Crescer 2018]. The National Autistic Society (2018) defines autism as a developmental disorder that manifests throughout life, affecting the way people communicate and relate others.

The autistic child has difficulty communicating effectively with other people. Often, she finds no motivation to relate to others. Thus, the child may experience delays in acquiring language skills, avoiding joining a group in social situations, as they believe that it isn't necessary to communicate [Wojciechowski and Al-Musawi 2017].

\subsection{Autism and Digital Games}

TEA patients can present excellent visual perception. Visual methods are often the best way to access the autistic children minds and support them in expressing themselves [Wojciechowski and Al-Musawi 2017]. In this context, several research kinds developed games for mobile devices (iPads, Tablets, among others). The games feature learning concepts in interactive ways to help children with autism learn, using mainly multimedia elements [Saleh et al. 2013].

Recently, the Pokemon GO application has drawn attention in autistic children context. This game presents a format that induces users to move through the real world in virtual monsters search with powers [GO 2017]. Also, there are reports that, with the Pokemon GO use, children with ASD changed their routines, leaving aside their isolation and improving their socialization [Hypescience 2016, Brasil 2016]. Then, the present paper aims to present a game that has the same format as gameplay. However, unlike Pokemon GO, each character the game can be associated with learning objects (OA). Sosteric and Hesemeier (2002) defines OA as hypermedia files that can be used directly to educational purposes, that contain suggestions on the use context.

\section{Related works}

This section presents a brief literature review on digital games to support learning to people with ASD. Applications developed a focus on improving communication and user socialization goals. 
Volioti et al. (2014) propose a virtual teaching environment based on social stories, designed to improve children's ability to solve social problems. The virtual space contains information about social situations for the child. Colpani, Homem, and Rodrigo (2016) use augmented reality and serious games the AR-G Educational Activities game project. The game provides activities grouping animals, fruits, and associating words to specific objects. These tasks encourage students with cognitive disabilities to explore, learn concepts and skills related to particular objects.

In a related context, Moura et al. (2016) propose TEO, a game suite that recreates games and activities commonly used in the people's traditional treatment with ASD. Games presented range from logical-mathematical games reasoning to games about everyday activities. Thus, children can learn from basic math operations to the dressing appropriate action.

The related works address some needs children's social and communicative with ASD. However, these studies still don't directly solve the social isolation problem for these children. The proposed paper uses a virtual character metaphor endowed with learning objects distributed geographically. Thus, through a mobile device, users can capture characteristics, view their contents, and break the social isolation geographical barrier.

\section{K-HUNTERS}

K-HUNTERS - the name proposed application - abbreviates Knowledgemon Hunters. The game provides a three-dimensional search and visualization environment for virtual characters with Learning Objects (LO). Your main interface features a three-dimensional avatar and a map portion the user's position. The device captures child's movement and coordinates. Figure 1.a) shows avatar and the game main interface in user's view.

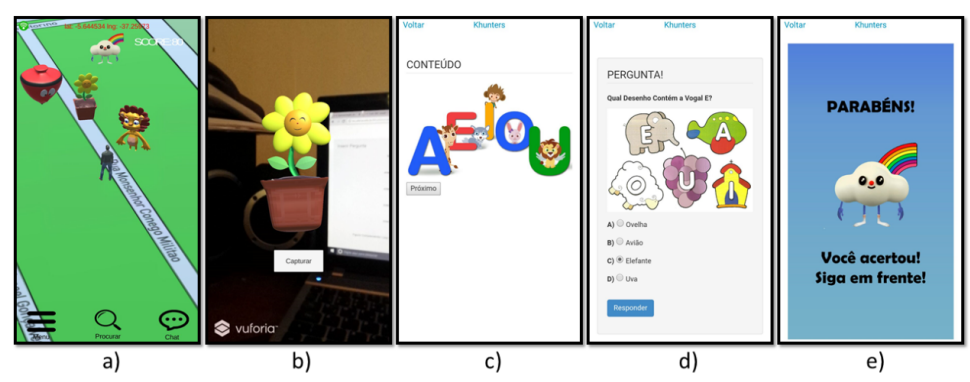

Figure 1. (a) Game interface with some virtual characters; (b) Character visualization by RA; (c) Viewing content by image; (d) Question about the content; (e) Incentive message

When the child moves in the real environment and approaches a virtual character geographical position, it appears in the main interface (as can be seen in Figure 1.a). From this moment on, by touching the device's screen, the child can capture characters, and it's possible to visualize them through augmented reality (Figure 1.b). We developed the characters' shape, color, movement, and sound based on animals present in assisted therapies, as they generally generate a particular empathy in children [Machado et al. 2008, Muñoz and Otta 2014].

When a child captures a character, it can access the learning object related to that character and, Through interactions with the game menus, viewing the information contained in learning objects (Figure 1.c) shows the visualization of content). After seeing the content, the child can answer questions related to the character's LO (Figure 1.d) shows 
this situation). It's worth mentioning that question's registration is optional and is the responsibility of those responsible for the child. When the child correctly answers questions, and congratulations image is displaying, and the algorithm adds points to his score (Figure 1.e) shows an incentive image). Otherwise, an incentive message is displayed to it to try again.

It's worth mentioning that learning objects insertion, characters three-dimensional models choice and the corresponding geographical position is the responsibility of educational psychologists or children's parents. Through a Web browser, those responsible can manage application content. Furthermore, this feature allows control of what children should see and ensures the insertion of the characters in safety locations.

The main interface also features a menu's, search, and chat buttons (Figure 1.a) shows these buttons at the bottom). The menu button allows, for example, the child to view captured characters, make adjustments to the game, their account log out, among other options. The search button allows the child to see styles available in geographic surroundings, making capture easier. Finally, the Chat button features a chat where users can send and display messages from other users who are nearby.

Besides, to game KHunters, we developed two games that work together with the first. These games make use of AR and VR to provide immersive and interactive environments. The next subsection presents the applications called K-Hunters Immersive and K-Hunters Find.

\subsection{Complementary Games}

K-Hunters Immersive (Figure 2.a) and Figure 2.b)) deals with a virtual and immersive environment where the child can interact with the content and characters captured in the game K-Hunters. This game is an immersive environment where it inserts the user, and Around it contains two interaction tables that show the captured character's learning objects contents. Behind the player's starting position is a panel containing characters captured in K-Hunters. The character that child-chosen to interact lies seen your front. Figure 2.a) shows the virtual environment structure and in Figures 2.b), 2.c), and 2.d) shows the environment during the game's execution.

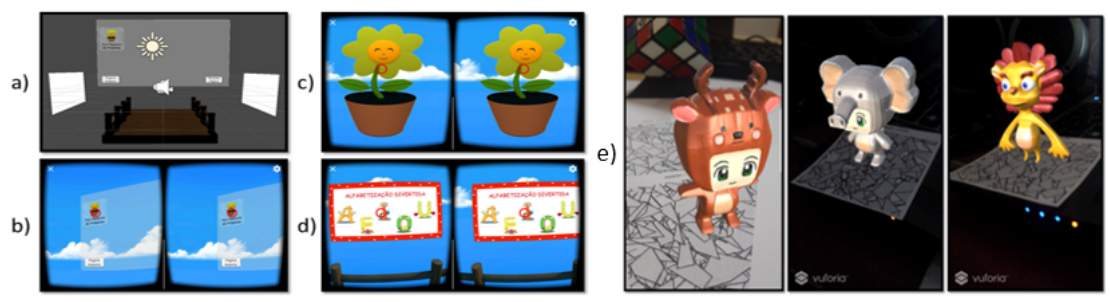

Figure 2. (a) Virtual environment's structure; (b) Character selection panel; (c) Character viewed in VR; (d) Content displayed on the board; (e) Game KHunters execution

K-Hunters Find displays the game characters based on RA. The idea is to associate each character with a specific image. Through the mobile device, the user can focus on the target image and view the character on RA. The game objective is to familiarize children with models of characters and teach them about their names. Figure 2.e) shows the game execution. 
As extra functionality, the application adapts the media of learning objects to the user's profile. Therefore, the game stores in ontologies the user's characteristics regarding autism and game usage data. A multi-agent system adapts to media. The following section explains the ontologies and multi-agent system.

\section{Ontologies and Multiagent System}

Diagnostic and Statistical Manual of Mental Disorders (DSM) developed by APA (American Psychiatric Association), currently in its fifth version, is the base of ontology that maintains the data of the autistics. According to the manual, five characteristics describe autism: A, B, C, D, and E [Association et al. 2014]. Ontology called DSMVAutism has in its structure five classes that represent the definitions A, B, C, D, and E of DSMV. The Classes were also defined to express each characteristic (low intensity, medium intensity, and high intensity). Figure 3 shows a part of the structure of this ontology.

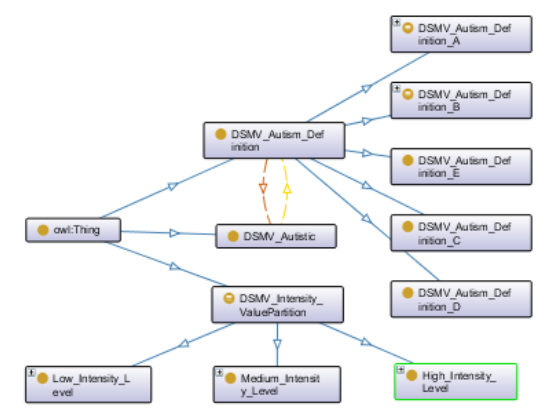

Figure 3. Structure's Part of the DSMVAutism ontology

The DSMV_Autism class is the parent class that represents the entire definition according to the manual. As child classes, there are five that describe the elements of DSM-V (A, B, C, D, and E). The DSMV_Intensity_ValuePartition class contains subclasses that represent the intensities with which the autism characteristics can manifest. Finally, the DSMV_Autistic class represents the game user. This class can relate to the class that contains autism definitions. In other words, the game relates characteristics describes in the DSMV_Autism_Definition class to the user in the ontology.

The second ontology stores game data and are called LearningStrategy. It has in its structure the following classes: User, Content, and Hypermedia. The User class represents the user and contains properties that allow players to store their personal information. The Content class represents content that a Learning Object (LO) can offer. There's also a property that will enable the range to be assigned a difficulty level (very easy, easy, average, difficult, very difficult). Hypermedia class represents media that an LO can contain (text, audio, video, etc.). Associated with Hypermedia class, there is a property that indicates the learning index associated with the media, that is, an average of how many questions users got right after consuming LO through media currently used. Figure 4 shows the ontology's part of the structure. 


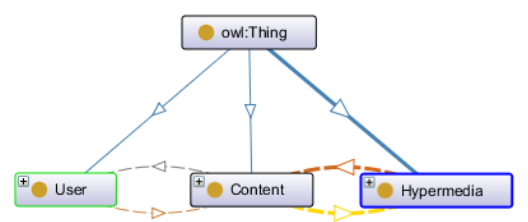

Figure 4. Structure's Part of the LearningStrategy ontology

Figure 4 makes it evident that there are relationships between User, Content, and Hypermedia. These relationships indicate that users access to content transmitted through some media. This ontology is used by a Multiagent System (MAS) that analyzes whether a specific media for sharing content is efficient, and based on this information, changes the strategy.

MAS has an agent defined as Strategy Manager (AgGE) responsible for determining content transmission strategies and changing OAs content transmission strategies. In the agent's first responsibility, when a user obtains a character, its content does not yet have a suitable media defined. AgGE starts checking with the strategy ontology, and the media more use by similar users (based on autistic profiles). If there are registered media, the children's characters receive the media. Otherwise, the default media for content is assigned (i.e., the hypermedia for the default content file at the registration time). The agent's second activity is to perform an analysis to determine if a particular media is efficient. Cyclically, in periods, AgGE checks children's learning rates in the strategy ontology. From these values, AgGE verifies that the utilization is below 60\%. In this case, it changes presentation media in the same process as the first activity described previously. Otherwise, the AgGE does nothing because the use is efficient. MAS also has a verifying agent $(\mathrm{AgV})$ responsible for communicating with databases, ontologies, and AgGE. AgV assists all processes performed by AgGE to data analysis.

\section{Games Validation}

This section presents the game's validations. Validation took place through a survey with seven special education expert teachers and three regular teachers from some municipal schools that work with students with ASD. Then subsections present the methodology used and the results obtained.

\subsection{Methodology}

We surveyed seven special education expert teachers and three regular teachers from schools in Mossoró-RN to validate the game. They work with children with ASD. We use TAM (Technology Acceptance Model) methodology to prepare the survey. The objective is to evaluate external factors related to an information system to the system's use and intentions use[Davis et al. 1989]. Davis (1989) [Davis et al. 1989] states that TAM uses Perceived Utility (the degree to which a person believes that using the system can improve their activities) and Ease of Use (the degree to which the person believes that using the system information is effortless).

The survey contains eight objective questions, using the Likert scale, and a space for comments. Likert scale addresses the subject's agreement level based on several statements that express favorable or unfavorable information to a psychological object [Likert 1976]. In this research, we use the following statements: Totally Disagree (TD); Partially Disagree (PD); Neutral (N); Partially Agree (PA); Strongly Agree (SA). 
In the first step, we create fictitious users for each professional and inserted characters in the places where we perform validation. Each character was associated with learning objects containing videos and images about teaching vowels. Our goal, when choosing this content, was to demonstrate that from each character, it is possible to have access to the media files, not aiming at the pedagogical nature.

In the second step, we demonstrate the objectives and functionalities of all games to professionals. The first game used was K-Hunter Find. At that moment, the participants using the game located the base images and visualized the character. The second game used was the game K-Hunters. The participant's first action was to login with their respective users. After login, the interface presented a map portion with the professional's geographical location. At that moment, the professionals viewed the characters that were previously registered and made their capture. During capture, they were able to see the character in AR and then access the learning object content. The third and last game used was K-Hunters Immersive. In this stage, the professionals used a virtual reality goggle. With the VR glasses, the professionals selected, from the character panel, one of the characters previously captured in the game K-Hunters. After the selection, we instructed to move his head by turning it to locate the character and the panels with the contents.

The third and last stage was applying the survey. We analyse data obtained from the proposal of Macnaughton (1996), Wilder Jr. (1978) and Davis (1989). The first considers the number of question's Agreements (AgrP) and Disagreements (DisP). They calculus the AgrP from the sum between the number of Strongly Agree and Partially Agree and DisP from the sum of the number of Totally Disagree and Partially Disagree responses [Macnaughton 1996]. Equations 1 and 2 are calculations for the two situations, respectively. With the values AgrP and DisP, Wilder Jr (1978) defined a formulation to define the Degree of Agreement of Each Proposition (DAP), shown in Equation 3.

$$
\begin{aligned}
& \operatorname{Agr} P=S A+P A+\frac{N}{2} \quad \text { (1) } D A P=100 *\left(\frac{A g r P}{(\operatorname{Agr} P+\operatorname{Dis} P)}\right) \\
& D i s P=T D+P D+\frac{N}{2} \quad \text { (2) }
\end{aligned}
$$

Based on the result of DAP, Davis (1989) proposed a table that indicates, in natural language, how much agreement or disagreement a person is to a given proposition. Table 1.(a) shows DAP values interpretation. 
IX Congresso Brasileiro de Informática na Educação (CBIE 2020)

Anais do XXXI Simpósio Brasileiro de Informática na Educação (SBIE 2020)

Table 1. DAP Values and Survey Statements

(a) Interpretations of DAP Values

\begin{tabular}{lc}
\hline \hline DAP value & Proper phrase \\
\hline \hline 90 or more & Extreme agreement \\
\hline 80 to $+89,99$ & Substantial agreement \\
\hline 70 to $+79,99$ & Moderate agreement \\
\hline 60 to $+69,99$ & Low agreement \\
\hline 50 to $+59,99$ & Negligible agreement \\
\hline 40 to $+49,99$ & Negligible disagreement \\
\hline 30 to $+39,99$ & Low disagreement \\
\hline 20 to $+29,99$ & Moderate disagreement \\
\hline 10 to +19.99 & Substantial disagreement \\
\hline 9.99 or less & Extreme disagreement \\
\hline \hline
\end{tabular}

(b) Survey statements

\begin{tabular}{cl}
\hline \hline & \multicolumn{1}{c}{ Ease of Use } \\
\hline \hline $\mathbf{N}^{\mathbf{0}}$ & Question \\
$\mathbf{1}$ & Do games offer an easy-to-interact interface to children? \\
$\mathbf{2}$ & Do the Games require a lot of effort to be used? \\
$\mathbf{3}$ & Was the learning dynamics of games ease? \\
\hline \hline & \multicolumn{1}{c}{ Perceived Utility } \\
\hline \hline $\mathbf{4}$ & Can games be used in intervention with children and \\
$\mathbf{5}$ & young people with Autism Spectrum Disorder? \\
$\mathbf{6}$ & Is it possible to use games as an aid to children's learning? \\
$\mathbf{7}$ & Is it possible to use games as a tool to minimize children's \\
& social isolation time? \\
$\mathbf{8}$ & $\begin{array}{l}\text { During games, is it possible to provide new experiences } \\
\text { that can enhance cognitive processes? }\end{array}$ \\
\hline \hline
\end{tabular}

\subsection{Results and discussions}

The first part of the survey refers to the game's Ease of Use. The second part presents questions related to the game's perceived usefulness. Table 1.(b) presents questions defined for this research.

Table 2.(a) presents comments received from experts in the comments area. This item, six experts, expressed their opinions demonstrating which factors influenced their choices. From Table 2.(a), it can be seen that experts indicate that games can be useful to minimize the social isolation time and assist in children's learning. Also, one of the game's differential factors is the inserting content possibility that can be accessed by children. Besides, they said they intend to use games in their activities with children.

Table 2.(b) shows the responeses number counted in each alternative and resulting in DisP, AgrP, and DAP values. This table, the maximum amount that DisP and AgrP can are ten since the maximum response number is ten.

\section{Table 2. Survey data and statements}

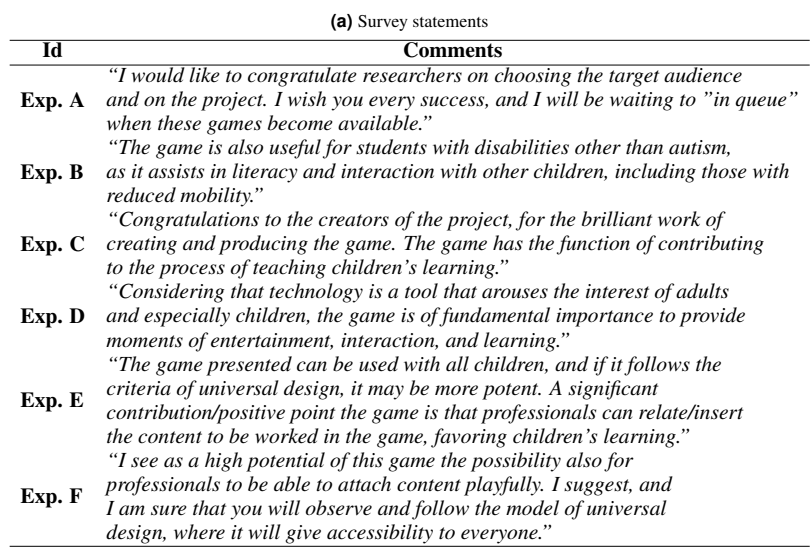

\begin{tabular}{|c|c|c|c|c|c|c|c|c|c|}
\hline \multicolumn{10}{|c|}{ (b) Survey Data } \\
\hline \multicolumn{10}{|c|}{ Ease of Use } \\
\hline Question & TD & PD & $\mathbf{N}$ & PA & SA & AMT & DisP & AgrP & DAP \\
\hline 1 & 0 & 0 & 0 & 8 & 2 & 10 & 0 & 10 & 100,00 \\
\hline 2 & 6 & 2 & 2 & 0 & 0 & 10 & 9 & 1 & 10,00 \\
\hline 3 & 0 & 0 & 0 & 6 & 4 & 10 & 0 & 10 & 100,00 \\
\hline \multicolumn{10}{|c|}{ Perceived Utility } \\
\hline 4 & 0 & 0 & 0 & 6 & 4 & 10 & 0 & 10 & 100,00 \\
\hline 5 & 0 & 0 & 0 & 3 & 7 & 10 & 0 & 10 & 100,00 \\
\hline 6 & 0 & 0 & 0 & 5 & 5 & 10 & 0 & 10 & 100,00 \\
\hline 7 & 0 & 1 & 0 & 6 & 3 & 10 & 1 & 9 & 90,00 \\
\hline 8 & 0 & 0 & 0 & 5 & 5 & 10 & 0 & 10 & 100,00 \\
\hline
\end{tabular}

From Table 2.(b), it's possible to note that, in both categories, experts strongly agree that games have an easy-to-interact interface, it is easy to learn their dynamics, and games are useful. However, they have a substantial disagreement with the statement that says that games require an effort lot to be used. To every question, DAP obtained 
was more significant than or equal to 90. Thus, we conclude that the experts an Extreme Agreement with most propositions. Hence, it indicates that they believe that children with ASD and others (who are not in this condition) can use the game and assist learning. Besides, it minimizes the social isolation time and also provides new experiences that enhance cognitive processes.

\section{Conclusion}

This paper addresses the issue: A Serious Geolocated Game can be used to minimize the time of social isolation and assist in the learning of children with Autism Spectrum Disorder? To answer the question, we propose a serious game with geolocation, designed to support learning and minimize the autistic children social isolation. The geoprocessing techniques use encourages children to explore the geographic space in which they live, considering that game demands fictional characters search and capture of scattered in space. Also, hypermedia visualization of the learning objects embedded characters allows children to view contents that can assist their knowledge.

Results achieved indicate that the games have the potential to achieve their goals. These results conclude that the games have an easy-to-use interface and can also help to learning and minimize the children's social isolation time with ASD. The main future research direction is the validation of the game with real users. This validation we will carry out collaborates with institutions specialized autism psycho-pedagogical monitoring, such as CAPSi (Center for Psychosocial Care and Children and Youth). These centers, we will carry sessions held to use games and check the game's effectiveness to the proposed objectives.

\section{References}

Association, A. P. et al. (2014). DSM-5: Manual diagnóstico e estatístico de transtornos mentais. Artmed Editora.

Braga, M. (2001). Realidade virtual e educação. Revista de biologia e ciências da terra, 1(1):0.

Brasil, B. (2016). "como pokémon go transformou vida de jovem com autismo que não conseguia sair de casa". http://www.bbc.com/portuguese/ geral-36964257. Acessado: 01-11-2019.

Brom, C., Preuss, M., and Klement, D. (2011). Are educational computer microgames engaging and effective for knowledge acquisition at high-schools? a quasiexperimental study. Computers \& Education, 57(3):1971-1988.

Camargo, S. P. H. and Bosa, C. A. (2009). Competência social, inclusão escolar e autismo: revisão crítica da literatura. Psicologia \& sociedade, 21(1):65-74.

Clinical Protocol, M. S. T. G. (2018). Classificação estatística internacional de doenças e problemas relacionados à saúde (cid-10).

Colpani, R., Homem, P., and Rodrigo, M. (2016). Realidade aumentada e gamificação na educação: uma aplicação para auxiliar no processo de aprendizagem de alunos com deficiência intelectual. Revista Brasileira de Informática na Educação, 24(1).

Crescer (2018). "autismo: 1 em cada 59 crianças está dentro do transtorno do espectro autista". https://revistacrescer. globo.com/Criancas/Comportamento/noticia/2018/04/ autismo-1-em-cada-59-criancas-estao-dentro-do-espectro-autista. html. Acessado: 01-11-2019. 
IX Congresso Brasileiro de Informática na Educação (CBIE 2020)

Anais do XXXI Simpósio Brasileiro de Informática na Educação (SBIE 2020)

Davis, F. D., Bagozzi, R. P., and Warshaw, P. R. (1989). User acceptance of computer technology: a comparison of two theoretical models. Management science, 35(8):9821003.

GO, P. (2017). "pokemon go". https://www.pokemongo.com/pt-pt/. Acessado: 01-11-2019.

Hypescience (2016). "como pokémon go está ajudando crianças com autism e aspeger". http://hypescience.com/ como-pokemon-go-esta-ajudando-criancas-com-autismo-e-asperger/. Acessado: 01-11-2019.

Likert, R. (1976). Una técnica para la medición de actitudes. CH Wainerman (comp.), Escalas de medición en ciencias sociales. Buenos Aires: Ediciones Nueva Visión, 1(99):260.

Machado, J. d. A. C., Rocha, J. R., Santos, L. M., and Piccinin, A. (2008). Terapia assistida por animais (taa). Revista científica eletrônica de medicina veterinária, 6(10):1-7.

Macnaughton, R. J. (1996). Numbers, scales, and qualitative research. The Lancet, 347(9008):1099-1100.

Moura, D., de Oliveira Filh, D. L. S., Laertius, D., Silva, A. J. G., Paiva, P., de Sales, T., Cavalcante, R., and Queiroz, F. (2016). Teo: Uma suite de jogos interativos para apoio ao tratamento de crianças com autismo. In Brazilian Symposium on Computers in Education (Simpósio Brasileiro de Informática na Educação-SBIE), volume 27, page 627.

Muñoz, P. d. O. L. and Otta, E. (2014). Terapia assistida por animais: Interação entre cães e crianças autistas.

Passerino, L. M. (2005). Pessoas com autismo em ambientes digitais de aprendizagem: estudo dos processos de interação social e mediação.

Saleh, M. S., Aljaam, J. M., Karime, A., and El Saddik, A. (2013). An edutainment system for assisting qatari children with moderate intellectual and learning disability through exerting physical activities. In 2013 IEEE Global Engineering Education Conference (EDUCON), pages 886-892. IEEE.

Society, N. A. (2018). "what is autism?". https : / / www . autism. org.uk/about/ what-is.aspx. Acessado: 01-11-2019.

Sosteric, M. and Hesemeier, S. (2002). When is a learning object not an object: A first step towards a theory of learning objects. The International Review of Research in open and distributed learning, 3(2).

Souza, H. (2016). Autismo use a tecnologia para ajudar. Disponível em.

Valente, J. A. (1997). O uso inteligente do computador na educação. Revista Pátio, 1(1):19-21.

Volioti, C., Tsiatsos, T., Mavropoulou, S., and Karagiannidis, C. (2014). Vlss-virtual learning and social stories for children with autism. In 2014 IEEE 14th International Conference on Advanced Learning Technologies, pages 606-610. IEEE.

Wilder, J. W. (1978). New concepts in technical trading systems. Trend Research.

Wojciechowski, A. and Al-Musawi, R. (2017). Assisstive technology application for enhancing social and language skills of young children with autism. Multimedia Tools and Applications, 76(4):5419-5439. 